\title{
Glutamate receptor antagonist suppresses the activation of nesfatin-1 neurons following refeeding or glucose administration
}

\author{
S. Serter Kocoglu1 ${ }^{1}$ C. Oy², Z. Halk², C. Cakır², Z. Minbay², O. Eyigor ${ }^{2}$ \\ 'Department of Histology and Embryology, Balikesir University School of Medicine, Balikesir, Turkey \\ ${ }^{2}$ Department of Histology and Embryology, Bursa Uludag University School of Medicine, Bursa, Turkey \\ [Received: 10 December 2020; Accepted: 3 March 2021; Early publication date: 22 March 2021]
}

Background: Nesfatin-1 is a newly identified satiety peptide that has regulatory effects on food intake and glucose metabolism, and is located in the hypothalamic nuclei, including the supraoptic nucleus (SON). In this study, we have investigated the hypothesis that nesfatin-1 neurons are activated by refeeding and intraperitoneal glucose injection and that the glutamatergic system has regulatory influences on nesfatin-1 neurons in the SON.

Materials and methods: The first set of experiments analysed activation of nesfatin-1 neurons after refeeding as a physiological stimulus and the effectiveness of the glutamatergic system on this physiological stimulation. The subjects were randomly divided into three groups: fasting group, refeeding group and antagonist (CNQX + refeeding) group. The second set of experiments analysed activation of nesfatin-1 neurons by glucose injection as a metabolic stimulus and the effectiveness of the glutamatergic system on this metabolic stimulation. The subjects were randomly divided into three groups: saline group, glucose group and antagonist (CNQX + glucose) group.

Results: Refeeding significantly increased the number of activated nesfatin-1 neurons by approximately $66 \%$, and intraperitoneal glucose injection activated these neurons by about 55\%, compared to the fasting and saline controls. The injections of glutamate antagonist (CNQX) greatly decreased the number of activated nesfatin-1 neurons.

Conclusions: This study suggested that nesfatin-1 neurons were activated by peripheral and/or metabolic signals and that this effect was mediated through the glutamatergic system. (Folia Morphol 2022; 81, 2: 379-386)

Key words: CNQX, glucose, glutamate, nesfatin-1, refeeding

\section{INTRODUCTION}

Nesfatin-1 is an 82 amino acid peptide that has modulating effects in regulating food intake, body weight and gluconeogenesis $[11,41]$. NUCB2/nesfatin-1 is widely expressed in peripheral tissues and the central nervous system [51]. Nesfatin-1 is expressed in the hypothalamic nuclei which are involved with the regulation of food intake including the paraventricular nucleus (PVN), arcuate nucleus (ARC), supraoptic nucleus (SON), lateral hypothalamic area (LHA), zona

Address for correspondence: Asst. Prof. S. Serter Koçoğlu, PhD, Balikesir University Faculty of Medicine, Department of Histology and Embryology, Balikesir, Turkey, Postal code: 10000, tel: +90 (266) 61210 10, fax: +90 (266) 61214 17, e-mail: serter_bio@hotmail.com

This article is available in open access under Creative Common Attribution-Non-Commercial-No Derivatives 4.0 International (CC BY-NC-ND 4.0) license, allowing to download articles and share them with others as long as they credit the authors and the publisher, but without permission to change them in any way or use them commercially. 
incerta, and the solitary tract $[11,23,41,43,44]$. NUCB2/nesfatin-1 has also shown to be expressed in the periphery such as the gastric mucosa, adipose tissue, ovaries, testes, uterus, epididymis, cardiomyocytes and pancreatic beta cells [41]. Surprisingly, NUCB2/nesfatin-1 immunoreactivity was found to be 10 times higher in the gastric mucosa than in the brain [15]. The inhibitory effects on food intake of nesfatin-1 have been studied and it has also been shown to influence the regulation of cardiac functions, lipid metabolism, glucose homeostasis and reproductive functions [5]. It has been shown that intracerebroventricular injection of nesfatin-1 into the $3^{\text {rd }}$ and $4^{\text {th }}$ ventricles reduces food intake in mice and rats $[29,35,44,49]$.

Immunohistochemically, the expression of transcription factors such as c-Fos, phosphorylated CREB or phosphorylated STATs (phosphorylated signal transducers and transcription activators) are used as markers for determining neuronal activity changes $[1,4,20,52]$. Nesfatin-1 injection to the $3^{\text {rd }}$ ventricle has been shown to cause c-Fos expression, especially in the PVN and the nucleus of the solitary tract [11, 29]. The expression of c-Fos in these nuclei shows the anorectic signalling mechanism of nesfatin-1 [11].

Glucose sensitive neurons include glucose homeostasis and glucoprivic feeding. Recently, these neurons have received more attention due to their regulatory effects on appetite [51]. Nesfatin-1 inhibits food intake by increasing the number of the glucose sensitive neurons in the hypothalamus (dorsal vagal complex) [51]. Nesfatin-1 participates in blood glucose regulation. Subcutaneous injection of nesfatin-1 reduces the glucose levels in the blood during the oral glucose tolerance test. However, intracerebroventricular injection of nesfatin-1 does not reduce glucose levels in the blood [28]. This finding suggests that the glycaemic effect of nesfatin-1 may be peripheral. Co-injection of insulin and nesfatin-1 increased the phosphorylation of AKT kinase in liver, skeletal muscle and adipose tissue. As a result, GluT4 expression increased to increase glucose uptake [15].

Glutamate is the major excitatory amino acid neurotransmitter in the mammalian central nervous system $[7,8]$. Glutamate plays an important role in the regulation of the neuroendocrine systems and the hypothalamus-pituitary-endocrine system axis by acting on many neuroendocrine and peptidergic neurons localised in the hypothalamus $[7,8,40]$. Glutamate-mediated neurotransmission occurs via metabotropic and ionotropic glutamate receptors [22]. Ionotropic glutamate receptors are classified according to their agonists: N-methyl-D-aspartate (NMDA), $\alpha$-amino-3-hydroxy-5-methyl-4-isoxazolepropionic acid (AMPA) and 2-carboxy-3-carboxymethyl-4-isopropenylpyrrolidine (kainate) receptors [22, 27, 45]. NMDA receptors are composed of subunits named GluN1, GluN2A-D and GluN3A-B $[9,24]$. These receptors have a critical function in excitatory synaptic transmission, plasticity and neurotoxicity [10,30,36-38].

Despite the many publications describing the mechanisms of action of nesfatin-1, there are no data about the peripheral and central control systems which play a role in the regulation of nesfatin-1 neuron activation. In this study, we analysed the effects of glutamatergic receptor antagonist (6-cyano-7-nitroquinoxaline-2.3-dione [CNQX]) on the activation of nesfatin-1 neurons following refeeding or glucose administration.

\section{MATERIALS AND METHODS}

Animals

All animal experiments were carried out in accordance with the National Institute of Health Guide for the Care and Use of Laboratory Animals and approved by the Experimental Ethics Committee of Bursa Uludag University (Date: 01.03.2016, No: HDP(T)-2016/25). Sixty-day-old male Sprague-Dawley rats (200-250 g) $(n=30)$, obtained from the Bursa Uludag University Laboratory Animal Breeding, Usage and Research Centre, were used in this study. Animals were kept in a light- and temperature-controlled facility (12:12 h light-dark cycle with lights off at 7:00 am and at $21^{\circ} \mathrm{C}$ ) with water freely available.

\section{Experimental groups}

\section{Experiment 1: Suppressive effect of glutamate receptor antagonist (CNQX) on nesfatin-1 neuronal activation induced by refeeding}

The animals were divided into three groups ( $n=5$ per group). After a 48-h fasting period, the refeeding group was allowed to eat ad libitum for $2 \mathrm{~h}$, while the fasting group was unfed and the antagonist group was injected intraperitoneally with non-NMDA glutamate antagonist (CNQX) $(2 \mathrm{mg} / \mathrm{kg}$ CNQX in $300 \mu \mathrm{L}$ distilled water, DW) $15 \mathrm{~min}$ before the 2-h refeeding period. After the 48-h fasting, refeeding was started at 9:00 am at the beginning of the dark period of the dark-light cycle and the animals were allowed to feed for $2 \mathrm{~h}$. Also, the CNQX injections were performed at 9:00 am. 
Experiment 2: Suppressive effect of glutamate receptor antagonist (CNQX) on nesfatin-1 neuronal activation induced by glucose injection

The animals were divided into three groups $(n=5$ per group). After a 48-h fasting period, the control group received saline ( $400 \mu \mathrm{L}$ saline, intraperitoneally [ip]), the glucose group was injected with glucose ( $2 \mathrm{~g} / \mathrm{kg}$ glucose in $400 \mu \mathrm{L}$ saline, ip) and the antagonist group was injected with non-NMDA glutamate antagonist ( $2 \mathrm{mg} / \mathrm{kg}$ CNQX in $400 \mu \mathrm{L}$ saline, ip) $15 \mathrm{~min}$ before the glucose injection. The dosage of glucose injection was determined by referring the previous reports in the literature $[21,46,47]$.

\section{Tissue preparation}

All injections were performed between 9:00 and 11:00 am and $90 \mathrm{~min}$ after injection, the animals were deeply anaesthetised with ether and fixed by trans-cardiac perfusion with $4 \%$ paraformaldehyde (PFA) in $0.13 \mathrm{M}$ Sorenson's phosphate buffer, $\mathrm{pH} 7.4$ ( $300 \mathrm{~mL} /$ animal). Brains and brainstems were carefully removed and post-fixed overnight in the same fixative at $+4^{\circ} \mathrm{C}$. Five series of brain sections with a thickness of $40 \mu \mathrm{m}$ were taken along the rostral-caudal axis of the hypothalamus with a vibratome and collected into Tris- $\mathrm{HCl}$ buffer $(0.05 \mathrm{M}, \mathrm{pH} 7.6)$. The brain sections were washed 3 times with Tris- $\mathrm{HCl}$ buffer $(0.05 \mathrm{M}$, $\mathrm{pH}$ 7.6) and then stored at $-20^{\circ} \mathrm{C}$ in cryoprotectant until use.

\section{Immunohistochemistry}

Tris- $\mathrm{HCl}$ buffer was used for all washing steps. Primary and secondary antibodies were diluted in blocking buffer $(10 \%$ normal horse serum, $0.2 \%$ Triton $\mathrm{X}-100$, and $0.1 \%$ sodium azide in Tris- $\mathrm{HCl}$ buffer) for $2 \mathrm{~h}$ in order to prevent non-specific binding. Following 2-h incubation in blocking buffer, sections were transferred into rabbit anti-c-Fos antibody solution at a dilution of 1/20 000 (Chemican, Billerica, MA, USA). The sections were incubated in donkey anti-rabbit IgG (1/300 dilution, Jackson ImmunoResearch Laboratories, West Grove, PA, USA) for $2 \mathrm{~h}$, processed with avidin-biotin complex according to the manufacturer's instructions ( $A B C$ Elite Standard Kit, Vector Laboratories, Burlingame, CA, USA) for $1 \mathrm{~h}$ and stained with diaminobenzidine (DAB) solution (25 mg DAB, $2 \mathrm{~g}$ nickel ammonium sulphate, $2.5 \mu \mathrm{L}$ hydrogen peroxide in $100 \mathrm{~mL}$ Tris-HCl buffer). After washing, the sections were secondarily blocked with $10 \%$ normal horse serum, and incubated in rabbit anti-nesfatin-1 antibody (1/20 000 dilution, $\mathrm{H}-060-50$, Phoenix Pharmaceuticals, Inc., USA) overnight at room temperature. This step was followed by secondary antibody incubation using biotin conjugated donkey anti-rabbit IgG (1/400 dilution, Jackson ImmunoResearch Labs, West Grove, PA, USA) for $2 \mathrm{~h}$. $\mathrm{DAB}(25 \mathrm{mg} \mathrm{DAB}, 2.5 \mu \mathrm{L}$ hydrogen peroxide in $50 \mathrm{~mL}$ Tris- $\mathrm{HCl}$ buffer) was used for visualisation of the immunochemical complex). Double-stained sections were then transferred into Tris-HCl buffer, washed, mounted on glass slides, dried and coverslipped with DPX.

c-Fos antibodies used in this study have been used in many reports in the literature as well as in our previous studies [17, 42]. Nesfatin-1 antibody specifity was shown in previous studies in the literature [6].

\section{Cell counting}

Sections were analysed and photographed with Olympus BX-50 photomicroscope attached to a CCD camera (Olympus DP71, CCD colour camera, 1.5 million pixels, Olympus Corporation, Japan). Sections between the coordinates determined according to the rat brain atlas (bregma $-0.48 \mathrm{~mm}$ and $-1.44 \mathrm{~mm}$ SON) were used for double immunohistochemical labelling [39]. Cross sections taken at five different levels at the same coordinate and at equal distance for each animal in the rostrocaudal plane were used for cell counting. All nesfatin-1-positive cells, with and without c-Fos-positive nuclei neurons in the SON were counted bilaterally and blindly in every fourth section between the stereotaxic coordinates of bregma $-0.48 \mathrm{~mm}-$ bregma $-1.44 \mathrm{~mm}$. Then the percentage of c-Fos-positive nesfatin-1 neurons to all nesfatin neurons was calculated within each animal in dual indirect immunoperoxidase-labelled sections.

\section{Statistical analysis}

The percentage of the c-Fos positivity in nesfatin- 1 positive cells is expressed as mean \pm standard deviation. The significance of differences between the groups was assessed with ANOVA test. The level of statistical significance was set at $p<0.05$. Statistical data analysis was performed with IBM SPSS, 23.0.

\section{RESULTS}

The agonist and antagonist injections did not cause adverse reactions or mortality during the experiments.

Nesfatin-1 positivity was visualized by brown reaction product with chromogen in the cytoplasm and 


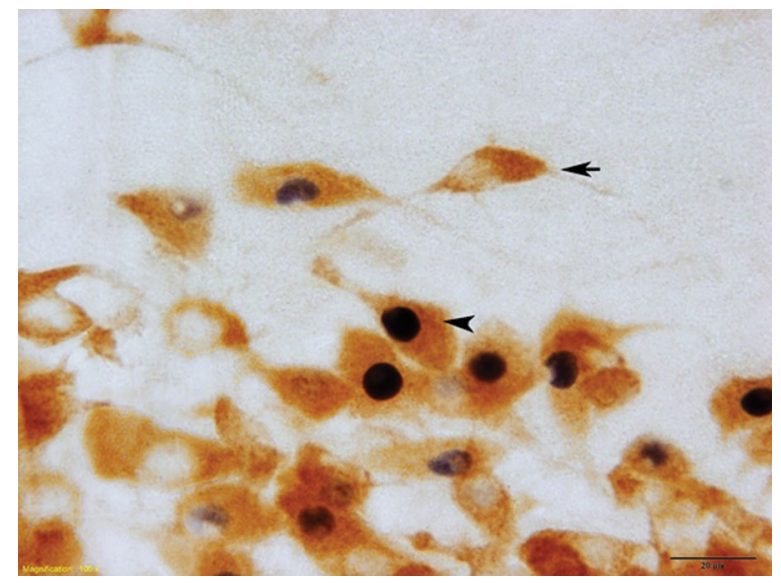

Figure 1. Representative c-Fos-positive and c-Fos-negative nesfatin-1 neurons. The arrow-head indicates c-Fos positivity (black) in the nucleus of a nesfatin-1-positive (brown) neuron. The arrow indicates a representative c-Fos-negative nesfatin-1 neuron.

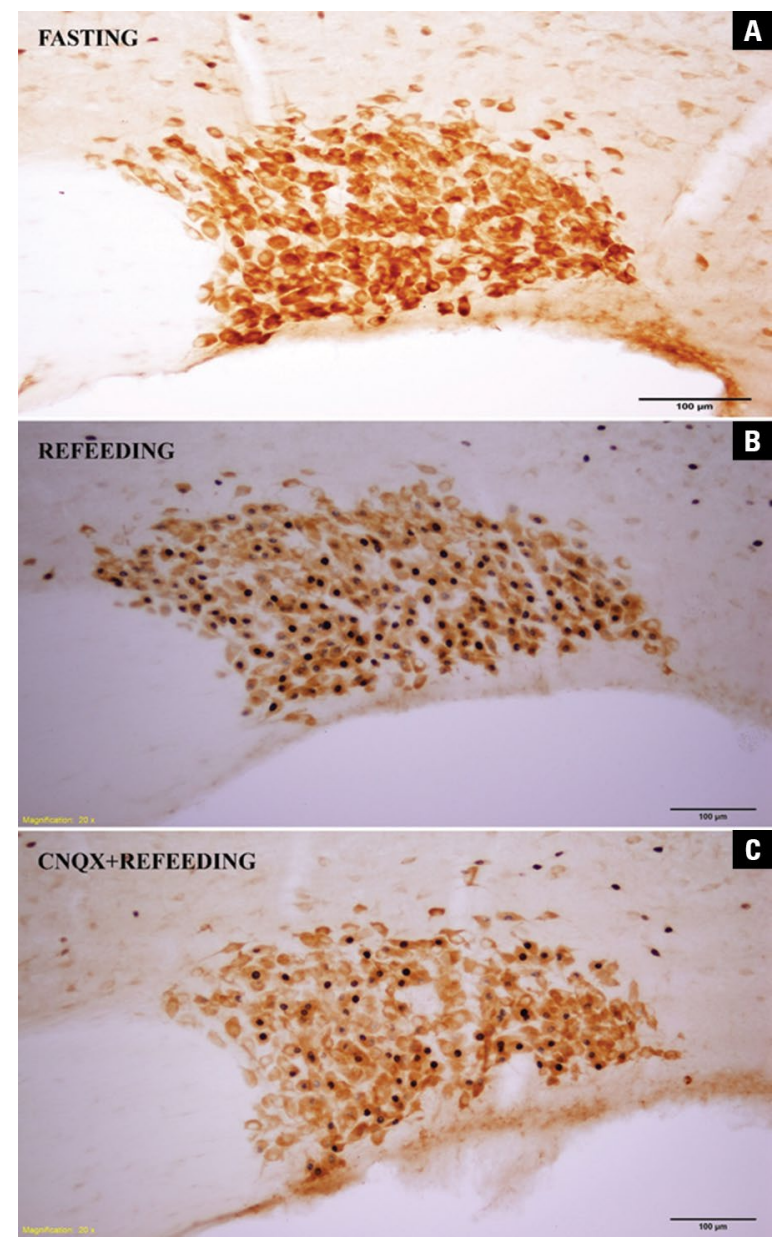

Figure 2. Effect of CNOX, a non-N-methyl-D-aspartate (NMDA) glutamate antagonist, in subjects stimulated by refeeding after fasting. Double-immunohistochemical staining of c-Fos and nesfatin-1 in supraoptic nucleus after $48 \mathrm{~h}$ fasting (A), after $2 \mathrm{~h}$ refeeding following $48 \mathrm{~h}$ fasting (B) and CNOX-treated subjects before feeding (C).
Table 1. The percentages of c-Fos-positive nesfatin-1 neurons relative to all nesfatin-1 neurons in all groups (mean \pm standard deviation). $P$ values pertain to the comparison with the refeeding and glucose-injected groups

\begin{tabular}{lcc}
\hline & \multicolumn{2}{c}{ c-Fos expression (\%) } \\
\cline { 2 - 3 } & Nesfatin-1 neurons & $\mathbf{P}$ \\
\hline Fasting & $1.00 \pm 0.94$ & $=0.00$ \\
Refeeding & $66.65 \pm 9.82$ & \\
CNOX + refeeding & $25.15 \pm 17.22$ & $<0.009$ \\
Glucose control & $1.13 \pm 0.66$ & $<0.01$ \\
Glucose & $55.7 \pm 21.46$ & \\
CNOX + glucose & $6.32 \pm 9.60$ & $<0.01$ \\
\hline CNOX - 6-cyano-7-nitroquinoxaline-23-dione
\end{tabular}

c-Fos positivity by blue/black reaction product in the nuclei (Fig. 1). After the 48-h fasting, refeeding and ip glucose injection significantly increased the number of c-Fos-expressing nesfatin-1 neurons, compared with the fasting and saline controls. These effects were also blocked by antagonist injection (CNQX).

\section{Refeeding induced c-Fos expression in nesfatin-1 neurons and CNQX reduced the number of active nesfatin-1 neurons}

After refeeding for $2 \mathrm{~h}$ following $48 \mathrm{~h}$ fasting, c-Fos-immunoreactive neurons were observed abundantly in the SON, PVN.

The 2-h refeeding after 48-h fasting caused a significant increase in the number of c-Fos-positive nesfatin-1 neurons compared with the fasting group. These effects were also blocked by antagonist (CNQX). In the refeeding group, about $66 \%$ of nesfatin-1 neurons localised in the SON were c-Fos-positive, whereas this ratio was $1 \%$ in the fasting group $(p=0.000)$. The ratio of the activated nesfatin-1 neurons was reduced to $25 \%$ after CNQX injection $(p=0.009)$. The number of nesfatin-1 neurons expressing c-Fos immunoreactivity was significantly (66 times) greater under refeeding, compared with fasting conditions (Figs. 2, 4A, Table 1).

\section{Glucose induced c-Fos expression in nesfatin-1 neurons and CNQX reduced the number of active nesfatin-1 neurons}

After glucose injection following $48 \mathrm{~h}$ fasting, c-Fos-immunoreactive neurons were observed abundantly in the SON, PVN.

The glucose injection after 48-h fasting significantly increased the number of c-Fos-positive nesfatin-1 


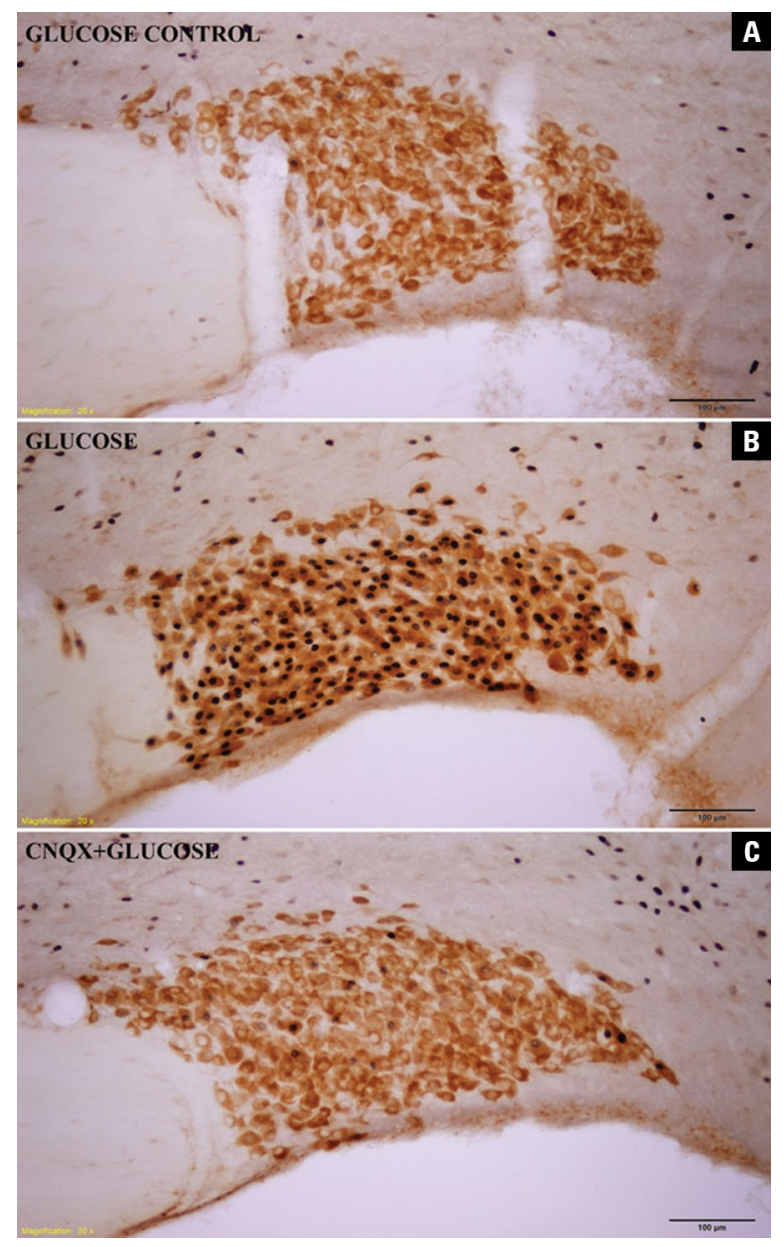

Figure 3. Effect of CNOX, a non-N-methyl-D-aspartate (NMDA) glutamate antagonist, in subjects stimulated by glucose injection. Double-immunohistochemical staining of c-Fos and nesfatin-1 in supraoptic nucleus, after $48 \mathrm{~h}$ fasting; saline injection (A), glucose injection (B) and CNOX-treated subjects before glucose injection (C).

neurons compared with the control group. These effects were also blocked by antagonist (CNQX). The glucose injection activated about $55 \%$ of c-Fos-positive neurons $(55 \%$, significantly more than in the control group: $1 \%, p=0.01$ ). The ratio of the activated nesfatin-1 clearly decreased after antagonist injection (CNQX) $(6 \%, p=0.01)$.

The number of c-Fos-expressing nesfatin-1 neurons was significantly increased following glucose injections when compared with saline conditions. The number of glucose-activated nesfatin-1 neurons was significantly reduced if CNQX was pre-injected (Figs. 3, 4B, Table 1).

\section{DISCUSSION}

Nesfatin-1 is a newly identified peptide that has regulatory effects on food and water intake, energy

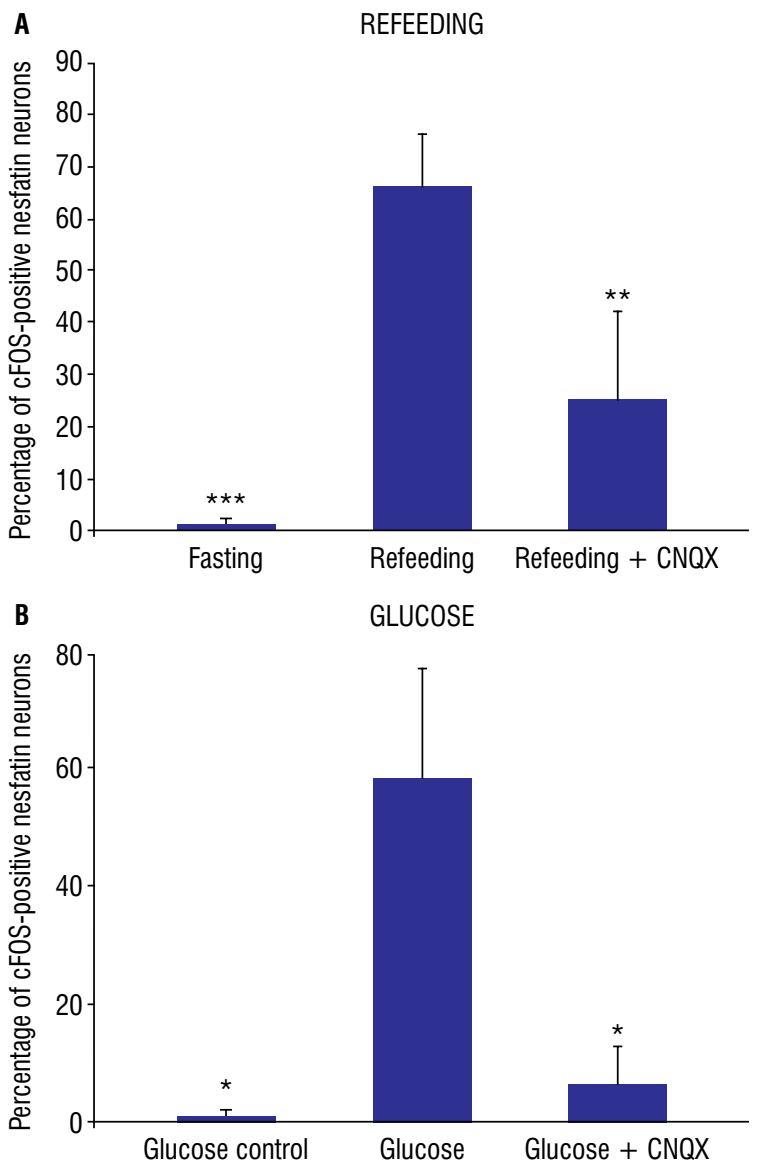

Figure 4. The percentages of c-Fos-positive nesfatin-1 neurons relative to all nesfatin-1 neurons. Effect of 6-cyano-7-nitroquinoxaline-2.3-dione (CNOX), a non-N-methyl-D-aspartate (NMDA) glutamate antagonist, in subjects stimulated by refeeding after fasting. There were significant differences between fasting-refeeding $\left(^{* * *} p<0.001\right)$ groups and refeeding-antagonist groups $\left({ }^{* *} p<0.01\right)$ (A). Effect of CNOX, a non-NMDA glutamate antagonist, in subjects stimulated by glucose injection. There were significant differences between glucose control-glucose and glucose-antagonist (CNQX + glucose) groups $\left({ }^{*} \mathrm{p}<0.05\right)(\mathrm{B})$.

consumption, cardiovascular and gastrointestinal functions, anxiety and depression and reproductive functions [41]. Although there is some literature on the effects of nesfatin-1 neurons in the target cells and organs, no experimental studies have been found on central neurotransmitter systems. In the present study, we investigated the hypothesis that nesfatin-1 neurons are activated by refeeding and glucose injection as peripheral and metabolic factors and that the glutamatergic system has regulatory influences on nesfatin-1 neurons in the SON.

The regulatory effects related to neurogenesis, apoptosis, neurite development and synapse formation of glutamate, the main excitatory neurotransmitter 
of the central nervous system, on the hypothalamic neuroendocrine systems, is intensively investigated [12-14, 32]. Glutamate is the dominant excitatory transmitter in neuroendocrine regulation in the hypothalamus. There were large amounts of glutamate in boutons making synaptic contact with neuroendocrine neurons in the arcuate, paraventricular, and supraoptic nuclei. The immunohistochemical studies showed that high level glutamate-immunoreactive terminals were present in the SON. Glutamate is also one of the major excitatory neurotransmitters in the SON [31]. In our laboratories we showed that kainic acid activates oxytocinergic neurons through non-NMDA glutamate receptors in the SON and PVN [34]. Our immunohistochemical studies showed that systemic administration of ionotropic non-NMDA and NMDA glutamate receptor agonists directly or indirectly activate neuronostatin neurons at different rates [42]. Also, we detected increased number of c-Fos positive nesfatin-1 neurons in kainic acid, AMPA and NMDA injected subjects in the SON [18]. In addition, expression of the ionotropic glutamate receptors has been demonstrated with fluorescence microscopy on nesfatin-1 neurons in the SON [18]. In the present study, after refeeding and glucose injection, c-Fos-immunoreactive neurons were observed abundantly in the SON. We analysed the SON for the effects of the glutamatergic system on nesfatin-1 neurons induced by refeeding and glucose injection.

The anorexigenic effect after injection into brain ventricles of nesfatin- 1 has been studied in various animal groups such as rats $[25,44,50]$, mice $[3,16]$, pigs [26] and goldfish [19], and it has been found to have a strong anorexigenic effect. Inhibition of dark phase food intake after third ventricle injection of nesfatin-1 has been described [35]. Low dose injection into the $4^{\text {th }}$ ventricle of nesfatin- 1 has been shown to reduce food intake in the first $4 \mathrm{~h}$ and suppress cumulative food intake in the $5^{\text {th }} \mathrm{h}$ [43]. Intracerebroventricular injection of nesfatin-1 has been shown to reduce water intake as well as food intake [48]. In the SON, refeeding has been shown to activate the number of nesfatin-1-immunoreactive neurons and mRNA expression of NUCB2 [23]. Refeeding after fasting also increased the number of c-Fos-positive nesfatin-1 neurons in the SON [23]. Our results not only confirmed this previous report by showing that activation of the nesfatin-1 neurons was caused by refeeding after fasting, but also that this activation was significantly suppressed by the administration of the AMPA/kainate receptor antagonist CNQX. This result suggests that the regulatory effect of glutamate on nesfatin-1 neurons is unique. In our previous study, we showed that 2-h refeeding after 48-h fasting induced PSTAT5 expression in the neuronostatin neurons in the anterior hypothalamic periventricular nucleus and this expression was significantly suppressed by glutamate receptor antagonist (CNQX) [42]. This information supports that a peripheral factor, such as refeeding, was effective in regulating the functions of nesfatin-1 neurons and that this effect was mediated through the glutamatergic system.

CNQX application to the fasting group was considered while designing the presented study. But in preliminary experiments, c-fos positivity was only $1 \%$ in nesfatin neurons in the fasting group. We did not use this group because we predicted that CNQX administration before fasting would not significantly change the activation of nesfatin neurons.

The hypothalamus plays an important role in regulating food intake and glucose homeostasis [33]. Glucose is the primary fuel for the brain and enters the central nervous system with the high-affinity glucose transporter (GLUT) type 1 [2]. Glucosensitive and glucoresponsive neurons are found in the hypothalamic nuclei and participate in glucose homeostasis [33]. Glucose-sensitive neurons are glucose-activated or glucose-inhibited neurons. Glucose-sensitive neurons are found in the hypothalamic nuclei such as ARC, PVN, SON, VMH, and lateral hypothalamus, and respond to blood glucose changes [33]. Neuronal activation of the hypothalamic nuclei after glucose infusion has been demonstrated using the c-Fos as the neuronal activation marker. The number of c-Fos-positive neurons peaks in $90 \mathrm{~min}$ after stimulus as a response to acute physiological stimuli. After intracarotid glucose injection, c-Fos, immunoreactive neurons are detected in PVN and VMH. The number of c-Fos-positive neurons in ARC and PVN was significantly higher than in the saline group [33]. We not only found that glucose injection after fasting dramatically increased the number of c-Fos immunoreactive-nesfatin-1 neurons in the SON but also determined that the number of active nesfatin-1 neurons was significantly reduced after glutamate receptor antagonist (CNQX) injections. This information suggests that nesfatin-1 neurons are glucose sensitive neurons and glutamatergic system regulates this mechanism.

In the present study, the increase in the number of activated nesfatin-1 neurons was observed to be 
about 66 -fold with refeeding and 55-fold with glucose injection after fasting. These results suggest that refeeding and/or glucose injection after fasting led to activation of nesfatin-1 neurons and this activation was mediated by the intracellular pathway with c-Fos. This data also supports the possibility of an intracellular pathway using c-Fos as the transcription factor, has a role in the regulation of the physiological activities of nesfatin-1 neurons. Furthermore, the number of activated nesfatin-1 neurons was significantly suppressed by glutamate receptor antagonist (CNQX) application. To our knowledge, this is the first report that has shown the regulatory effect of glutamatergic system on nesfatin-1 neurons. Our previous studies supports that glutamate receptor antagonist (CNQX) can reach the central nervous system and affect the neuronal activation $[13,18,34,42]$. Also, our data showed that nesfatin-1 neurons express glutamate receptor subunits [18]. Taken together, we can suggest that glutamatergic signals may reach the nesfatin-1 neurons directly. Another possibility of course is that an indirect mechanism involving glutamate-receptive interneurons may play a role in the regulation of nesfatinergic system.

It is important to implicate that the immunohistochemistry is limited to the detectable levels of the proteins that are analysed in this study. Our results only include the nesfatin-1 neurons that can be identified by immunohistochemistry, and the numbers provided in this study only represents these neurons.

\section{CONCLUSIONS}

In conclusion, this study demonstrated that refeeding and glucose intake highly selectively activates nesfatin-1 neurons in the SON. This activation suggests that nesfatin-1 neurons in the SON may play a role in the regulation of feeding behaviour and glucose metabolism. The results also demonstrated that glutamate antagonist CNQX can specifically block this activation, suggesting that this effect was mediated through the glutamatergic system.

\section{Conflict of interest: None declared}

\section{REFERENCES}

1. Altarejos JY, Montminy M. CREB and the CRTC co-activators: sensors for hormonal and metabolic signals. Nat Rev Mol Cell Biol. 2011; 12(3): 141-151, doi: 10.1038/nrm3072, indexed in Pubmed: 21346730.

2. Alvarsson A, Stanley SA. Remote control of glucose-sensing neurons to analyze glucose metabolism. Am J Physiol Endocrinol Me- tab. 2018; 315(3): E327-E339, doi: 10.1152/ajpendo.00469.2017, indexed in Pubmed: 29812985.

3. Atsuchi K, Asakawa A, Ushikai M, et al. Centrally administered nesfatin-1 inhibits feeding behaviour and gastroduodenal motility in mice. Neuroreport. 2010; 21(15): 1008-1011, doi: 10.1097/ WNR.0b013e32833f7b96, indexed in Pubmed: 20827224.

4. Balazs R. Trophic effect of glutamate. Curr Top Med Chem. 2006; 6(10): 961-968, doi: 10.2174/156802606777323700.

5. Blanco AM, Velasco C, Bertucci Jl, et al. Nesfatin-1 regulates feeding, glucosensing and lipid metabolism in rainbow trout. Front Endocrinol (Lausanne). 2018; 9: 484, doi: 10.3389/fendo.2018.00484, indexed in Pubmed: 30210451.

6. Brailoiu GC, Dun SL, Brailoiu E, et al. Nesfatin-1: distribution and interaction with a $\mathrm{G}$ protein-coupled receptor in the rat brain. Endocrinology. 2007; 148(10): 5088-5094, doi: 10.1210/en.20070701, indexed in Pubmed: 17627999.

7. Brann DW. Glutamate: a major excitatory transmitter in neuroendocrine regulation. Neuroendocrinology. 1995; 61(3): 213-225, doi: 10.1159/000126843, indexed in Pubmed: 7898626.

8. Brann D, Mahesh V. Excitatory amino acids: function and significance in reproduction and neuroendocrine regulation. Front Neuroendocrinol. 1994; 15(1): 3-49, doi: 10.1006/frne.1994.1002.

9. Collingridge GL, Olsen RW, Peters J, et al. A nomenclature for ligand-gated ion channels. Neuropharmacology. 2009; 56(1): 2-5, doi: 10.1016/j.neuropharm.2008.06.063, indexed in Pubmed: 18655795.

10. Cull-Candy S, Brickley S, Farrant M. NMDA receptor subunits: diversity, development and disease. Curr Opin Neurobiol. 2001; 11(3): 327-335, doi: 10.1016/s0959-4388(00)00215-4, indexed in Pubmed: 11399431.

11. Dong J, Guan $\mathrm{HZ}$, Jiang $Z Y$, et al. Nesfatin-1 influences the excitability of glucosensing neurons in the dorsal vagal complex and inhibits food intake. PLoS One. 2014; 9(6): e98967, doi: 10.1371/ journal.pone.0098967, indexed in Pubmed: 24906120.

12. Eyigor O, Centers A, Jennes L. Distribution of ionotropic glutamate receptor subunit mRNAs in the rat hypothalamus. J Comp Neurol. 2001; 434(1): 101-124, doi: 10.1002/cne.1167, indexed in Pubmed: 11329132

13. Eyigor O, Minbay Z, Cavusoglu I. Activation of orexin neurons through non-NMDA glutamate receptors evidenced by c-Fos immunohistochemistry. Endocrine. 2010; 37(1): 167-172, doi: 10.1007/s12020-009-9284-x, indexed in Pubmed: 20963566.

14. Eyigor O, Minbay Z, Cavusoglu I, et al. Localization of kainate receptor subunit GluR5-immunoreactive cells in the rat hypothalamus. Brain Res Mol Brain Res. 2005; 136(1-2): 38-44, doi: 10.1016/j. molbrainres.2005.01.015, indexed in Pubmed: 15893585.

15. Fan XT, Tian Z, Li SZ, et al. Ghrelin receptor Is required for the effect of nesfatin-1 on glucose metabolism. Front Endocrinol (Lausanne). 2018; 9: 633, doi: 10.3389/fendo.2018.00633, indexed in Pubmed: 30405536.

16. Goebel M, Stengel A, Wang L, et al. Central nesfatin-1 reduces the nocturnal food intake in mice by reducing meal size and increasing inter-meal intervals. Peptides. 2011; 32(1): 36-43, doi: 10.1016/j. peptides.2010.09.027, indexed in Pubmed: 20933030.

17. Gok-Yurtseven D, Kafa IM, Minbay Z, et al. Glutamatergic activation of $A 1$ and $A 2$ noradrenergic neurons in the rat brain stem. Croat Med J. 2019; 60(4): 352-360, indexed in Pubmed: 31483121.

18. Gok Yurtseven D, Serter Kocoglu S, Minbay Z, et al. Immunohistochemical evidence for glutamatergic regulation of nesfatin-1 neurons in the rat hypothalamus. Brain Sci. 2020; 10(9), doi: 10.3390/brainsci10090630, indexed in Pubmed: 32932902.

19. Gonzalez R, Kerbel B, Chun A, et al. Molecular, cellular and physiological evidences for the anorexigenic actions of nesfatin-1 in goldfish. PLoS One. 2010; 5(12): e15201, doi: 10.1371/journal. pone.0015201, indexed in Pubmed: 21151928.

20. Hoffman GE, Lyo D. Anatomical markers of activity in neuroendocrine systems: are we all 'fos-ed out'? J Neuroendocrinol. 2002; 
14(4): 259-268, doi: 10.1046/j.1365-2826.2002.00775.x, indexed in Pubmed: 11963822.

21. Huo L, Gamber K, Greeley S, et al. Leptin-dependent control of glucose balance and locomotor activity by POMC neurons. Cell Metab. 2009; 9(6): 537-547, doi: 10.1016/j.cmet.2009.05.003, indexed in Pubmed: 19490908.

22. Kew JNC, Kemp JA. lonotropic and metabotropic glutamate receptor structure and pharmacology. Psychopharmacology (Berl). 2005; 179(1): 4-29, doi: 10.1007/s00213-005-2200-z, indexed in Pubmed: 15731895.

23. Kohno $D$, Nakata $M$, Maejima $Y$, et al. Nesfatin-1 neurons in paraventricular and supraoptic nuclei of the rat hypothalamus coexpress oxytocin and vasopressin and are activated by refeeding. Endocrinology. 2008; 149(3): 1295-1301, doi: 10.1210/en.20071276, indexed in Pubmed: 18048495.

24. Köles L, Wirkner K, Illes P. Modulation of ionotropic glutamate receptor channels. Neurochem Res. 2001; 26(8-9): 925-932, doi: 10.1023/a:1012380416876, indexed in Pubmed: 11699944.

25. Könczöl K, Pintér $O$, Ferenczi S, et al. Nesfatin-1 exerts long-term effect on food intake and body temperature. Int J Obes (Lond). 2012; 36(12): 1514-1521, doi: 10.1038/ijo.2012.2, indexed in Pubmed: 22290539 .

26. Lents CA, Barb CR, Hausman GJ, et al. Effects of nesfatin-1 on food intake and $\mathrm{LH}$ secretion in prepubertal gilts and genomic association of the porcine NUCB2 gene with growth traits. Domest Anim Endocrinol. 2013; 45(2): 89-97, doi: 10.1016/j. domaniend.2013.06.002, indexed in Pubmed: 23820242.

27. Lerma J, Paternain AV, Rodríguez-Moreno A, et al. Molecular physiology of kainate receptors. Physiol Rev. 2001; 81(3): 971-998, doi: 10.1152/physrev.2001.81.3.971, indexed in Pubmed: 11427689.

28. Li Z, Gao L, Tang H, et al. Peripheral effects of nesfatin-1 on glucose homeostasis. PLoS One. 2013; 8(8): e71513, doi: 10.1371/journal. pone.0071513, indexed in Pubmed: 23967220.

29. Maejima Y, Sedbazar U, Suyama S, et al. Nesfatin-1-regulated oxytocinergic signaling in the paraventricular nucleus causes anorexia through a leptin-independent melanocortin pathway. Cell Metab. 2009; 10(5): 355-365, doi: 10.1016/j.cmet.2009.09.002, indexed in Pubmed: 19883614.

30. Mayer ML. Structural biology of glutamate receptor ion channel complexes. Curr Opin Struct Biol. 2016; 41: 119-127, doi: 10.1016/j.sbi.2016.07.002, indexed in Pubmed: 27454049.

31. Meeker RB, Greenwood RS, Hayward JN. Glutamate is the major excitatory transmitter in the supraoptic nuclei. Ann N Y Acad Sci. 1993; 689: 636-639, doi: 10.1111/j.1749-6632.1993.tb55614.x, indexed in Pubmed: 8103978.

32. Meeker RB, McGinnis S, Greenwood RS, et al. Increased hypothalamic glutamate receptors induced by water deprivation. Neuroendocrinology. 1994; 60(5): 477-485, doi: 10.1159/000126784, indexed in Pubmed: 7531299.

33. Miñana-Solis MD, Angeles-Castellanos M, Buijs RM, et al. Altered Fos immunoreactivity in the hypothalamus after glucose administration in pre- and post-weaning malnourished rats. Nutr Neurosci. 2010; 13(4): 152-160, doi: 10.1179/147683010X12611460764246, indexed in Pubmed: 20670470.

34. Minbay FZ, Eyigor O, Cavusoglu I. Kainic acid activates oxytocinergic neurons through non-nmda glutamate receptors. Int J Neurosci. 2006; 116(5): 587-600, doi: 10.1080/00207450600592123, indexed in Pubmed: 16644519.

35. Oh-I S, Shimizu H, Satoh T, et al. Identification of nesfatin-1 as a satiety molecule in the hypothalamus. Nature. 2006; 443(7112): 709-712, doi: 10.1038/nature05162, indexed in Pubmed: 17036007.

36. Ozawa S, Kamiya H, Tsuzuki K. Glutamate receptors in the mammalian central nervous system. Prog Neurobiol. 1998; 54(5): 581-618, doi: 10.1016/s0301-0082(97)00085-3, indexed in Pubmed: 9550192.
37. Pachernegg S, Strutz-Seebohm N, Hollmann M. GluN3 subunit-containing NMDA receptors: not just one-trick ponies. Trends Neurosci. 2012; 35(4): 240-249, doi: 10.1016/j.tins.2011.11.010, indexed in Pubmed: 22240240.

38. Paoletti P. Molecular basis of NMDA receptor functional diversity. Eur J Neurosci. 2011; 33(8): 1351-1365, doi: 10.1111/j.14609568.2011.07628.x, indexed in Pubmed: 21395862.

39. Paxinos G, Watson C. The rat brain in stereotaxic coordinates. Acad Press, London 2009.

40. Samson WK, Zhang JV, Avsian-Kretchmer O, et al. Neuronostatin encoded by the somatostatin gene regulates neuronal, cardiovascular, and metabolic functions. J Biol Chem. 2008; 283(46): 31949-31959, doi: 10.1074/jbc.M804784200, indexed in Pubmed: 18753129.

41. Schalla MA, Stengel A. Current understanding of the role of nesfatin-1. J Endocr Soc. 2018; 2(10): 1188-1206, doi: 10.1210/ js.2018-00246, indexed in Pubmed: 30302423.

42. Serter Kocoglu S, Gok Yurtseven D, Cakir C, et al. Glutamatergic activation of neuronostatin neurons in the periventricular nucleus of the hypothalamus. Brain Sci. 2020; 10(4), doi: 10.3390/brainsci10040217, indexed in Pubmed: 32268550.

43. Stengel A, Goebel M, Taché Y. Nesfatin-1: a novel inhibitory regulator of food intake and body weight. Obes Rev. 2011; 12(4): 261-271, doi: 10.1111/j.1467-789X.2010.00770.x, indexed in Pubmed: 20546141.

44. Stengel A, Goebel M, Wang L, et al. Central nesfatin-1 reduces dark-phase food intake and gastric emptying in rats: differential role of corticotropin-releasing factor2 receptor. Endocrinology. 2009; 150(11): 4911-4919, doi: 10.1210/en.2009-0578, indexed in Pubmed: 19797401

45. Tse YC, Yung KK. Cellular expression of ionotropic glutamate receptor subunits in subpopulations of neurons in the rat substantia nigra pars reticulata. Brain Res. 2000; 854(1-2): 57-69, doi: 10.1016/s0006-8993(99)02292-1, indexed in Pubmed: 10784107.

46. Üner A, Gonçalves GHM, Li W, et al. The role of GluN2A and GluN2B NMDA receptor subunits in AgRP and POMC neurons on body weight and glucose homeostasis. Mol Metab. 2015; 4(10): 678-691, doi: 10.1016/j.molmet.2015.06.010, indexed in Pubmed: 26500840.

47. Üner AG, Keçik O, Quaresma PGF, et al. Role of POMC and AgRP neuronal activities on glycaemia in mice. Sci Rep. 2019; 9(1): 13068, doi: 10.1038/s41598-019-49295-7, indexed in Pubmed: 31506541.

48. Yosten GLC, Redlinger L, Samson WK. Evidence for a role of endogenous nesfatin- 1 in the control of water drinking. J Neuroendocrinol. 2012; 24(7): 1078-1084, doi: 10.1111/j.13652826.2012.02304.x, indexed in Pubmed: 22375892.

49. Yosten GLC, Samson WK. Nesfatin-1 exerts cardiovascular actions in brain: possible interaction with the central melanocortin system. Am J Physiol Regul Integr Comp Physiol. 2009; 297(2): R330-R336, doi: 10.1152/ajpregu.90867.2008, indexed in Pubmed: 19474390.

50. Yosten GLC, Samson WK. The anorexigenic and hypertensive effects of nesfatin- 1 are reversed by pretreatment with an oxytocin receptor antagonist. Am J Physiol Regul Integr Comp Physiol. 2010; 298(6): R1642-R1647, doi: 10.1152/ajpregu.00804.2009, indexed in Pubmed: 20335376.

51. Yuan JH, Chen Xi, Dong J, et al. Nesfatin-1 in the lateral parabrachial nucleus inhibits food intake, modulates excitability of glucosensing neurons, and enhances UCP1 expression in brown adipose tissue. Front Physiol. 2017; 8: 235, doi: 10.3389/fphys.2017.00235, indexed in Pubmed: 28484396.

52. Zhao JB, Zhang Y, Li GZ, et al. Activation of JAK2/STAT pathway in cerebral cortex after experimental traumatic brain injury of rats. Neurosci Lett. 2011; 498(2): 147-152, doi: 10.1016/j.neulet.2011.05.001, indexed in Pubmed: 21596098. 